
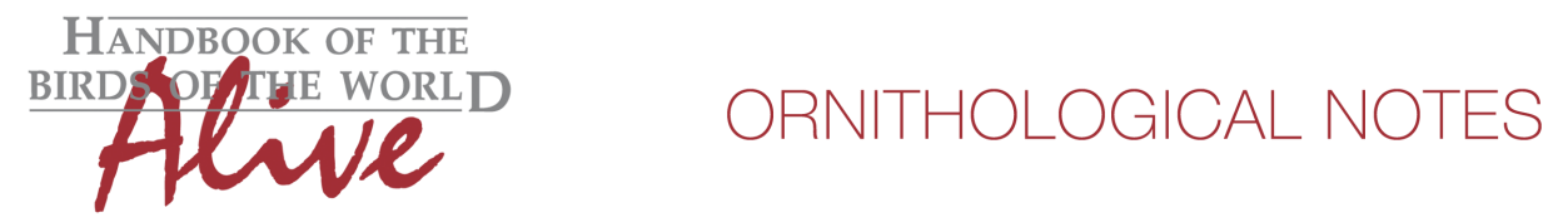

\title{
Notes on the vocalizations of Plain Softtail (Thripophaga fusciceps)
}

Peter Boesman

In the following we briefly analyze and compare voice of the different races of Plain Softtail (Thripophaga fusciceps). We also try to quantify the extent of any vocal differences using the criteria proposed by Tobias et al. (2010), as a support for taxonomic review.

We have made use of sound recordings available on-line from Xeno Canto (XC) and Macaulay Library (ML).

Song of all 3 races is a long chatter (in which often 2 or more birds participate).

By ear, it is obvious that dimorpha (both from Ecuador and SE Peru) sounds much higherpitched than fusciceps (with obidensis closer to dimorpha).

A closer inspection of sonograms of the song reveals the following:

\section{dimorpha}

A rising and falling fairly harsh rattle gradually shifting into more stuttering rattling salvo's. The salvo's consisting of 1-3 higher-pitched notes followed by a faster series of lower-pitched notes at even pitch.

total chatter:

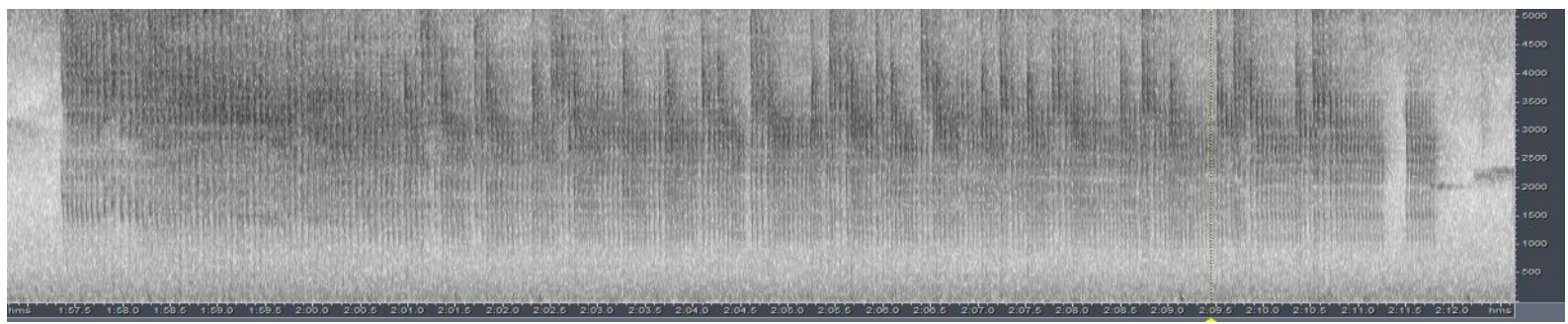

single salvo:

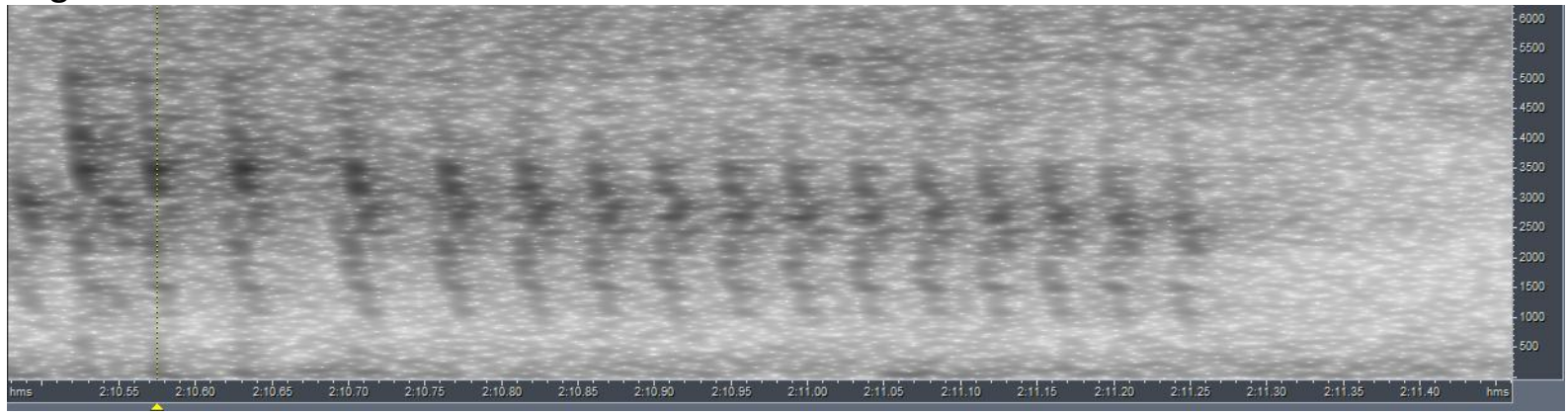

two salvo's:

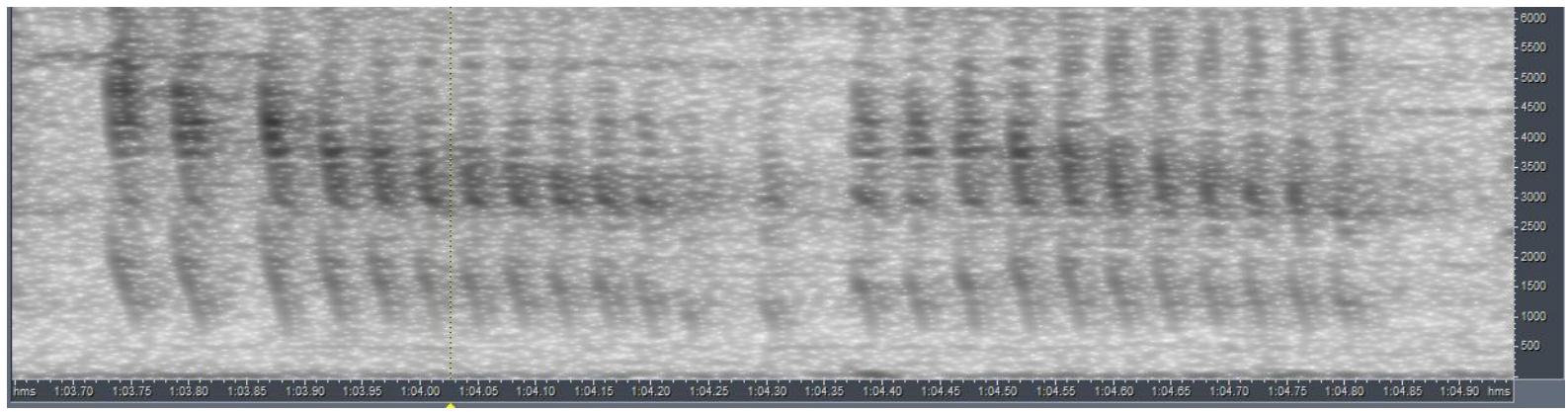




\section{HANDBOOK OF THE BIRDSPIJUE WORLD}

\section{ORNITHOLOGICAL NOTES}

\section{fusciceps}

As in dimorpha, starting with a harsh rattle and followed by stuttering rattling salvo's, which seem to have fewer notes compared to previous.

total chatter:

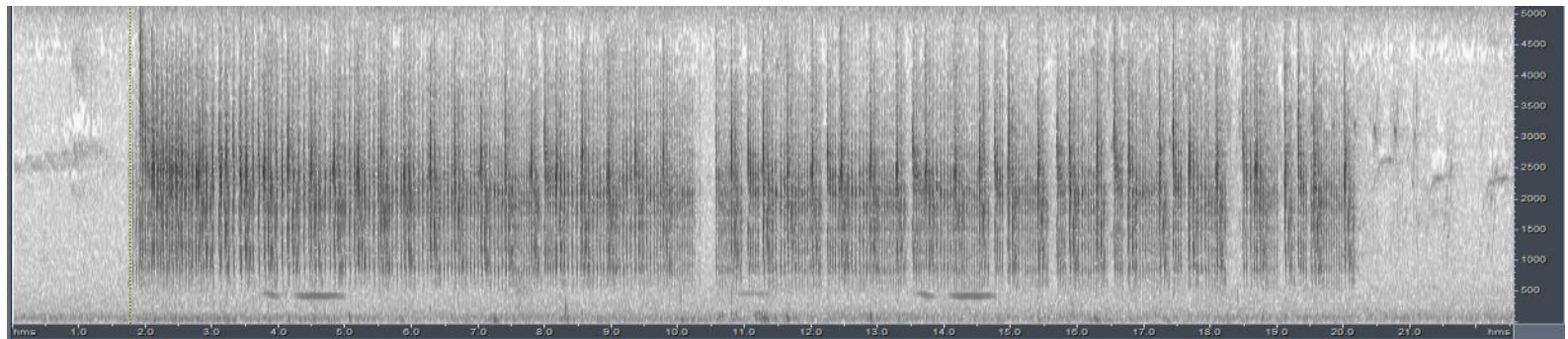

a few salvo's:

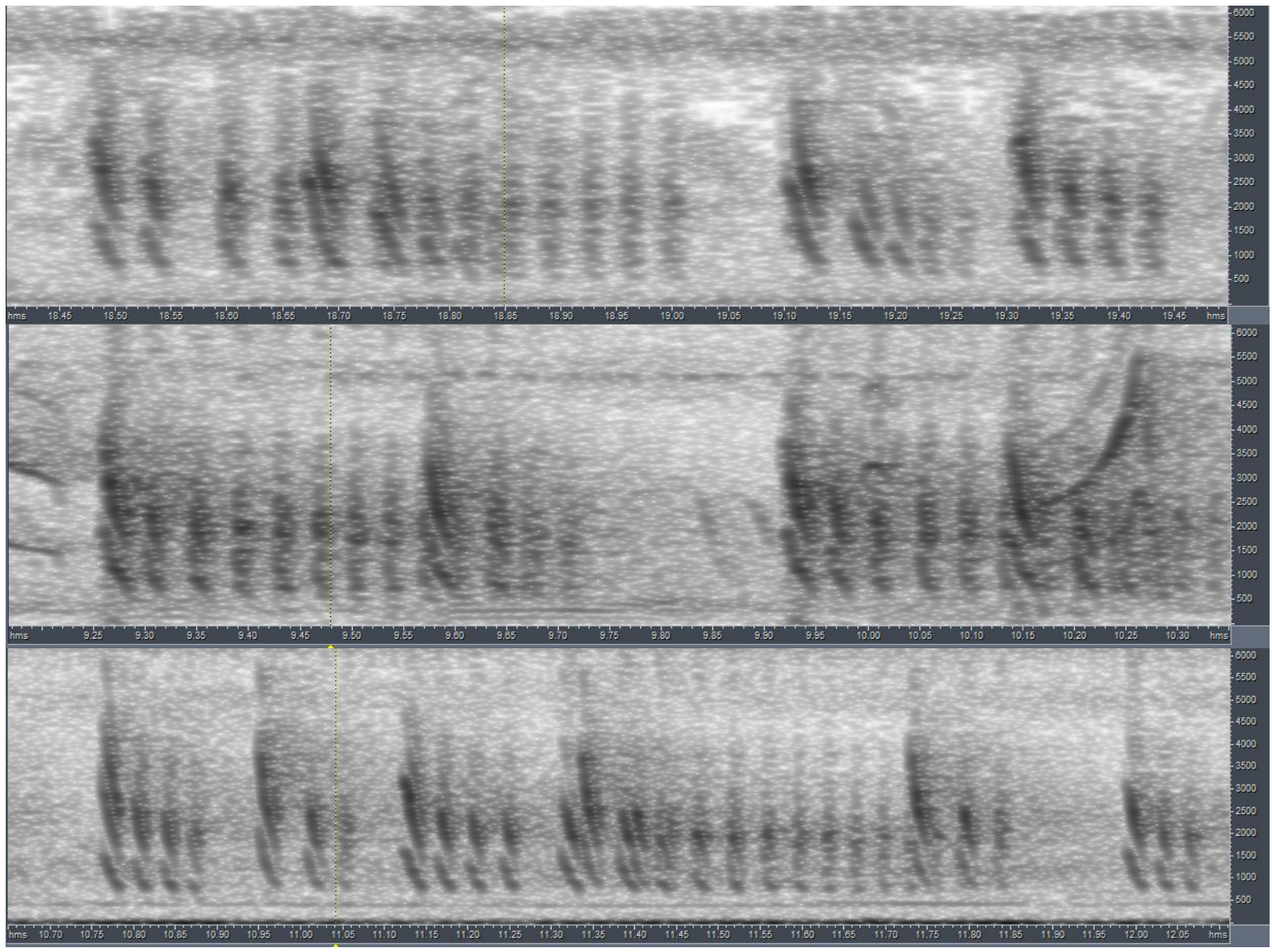




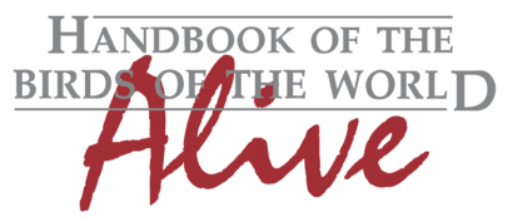

\section{ORNITHOLOGICAL NOTES}

\section{obidensis}

total chatter:

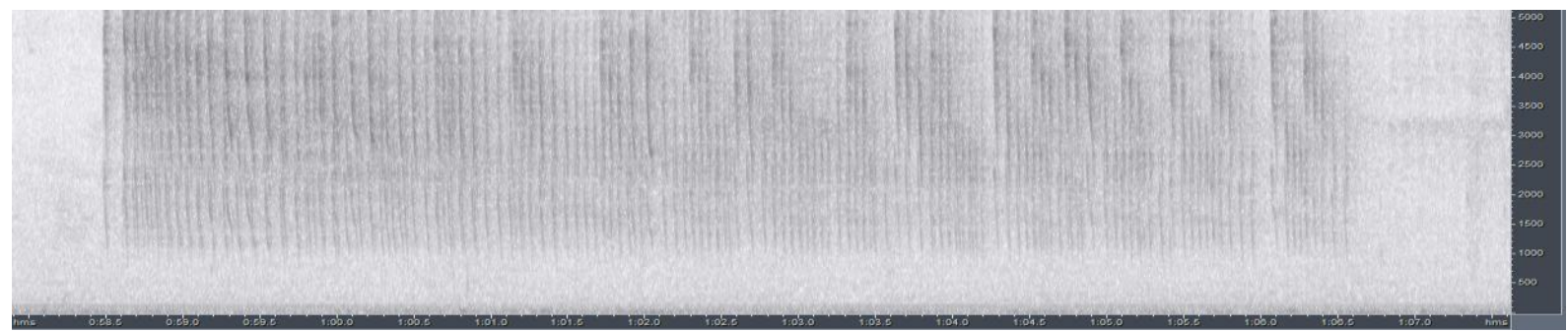

a few salvo's:

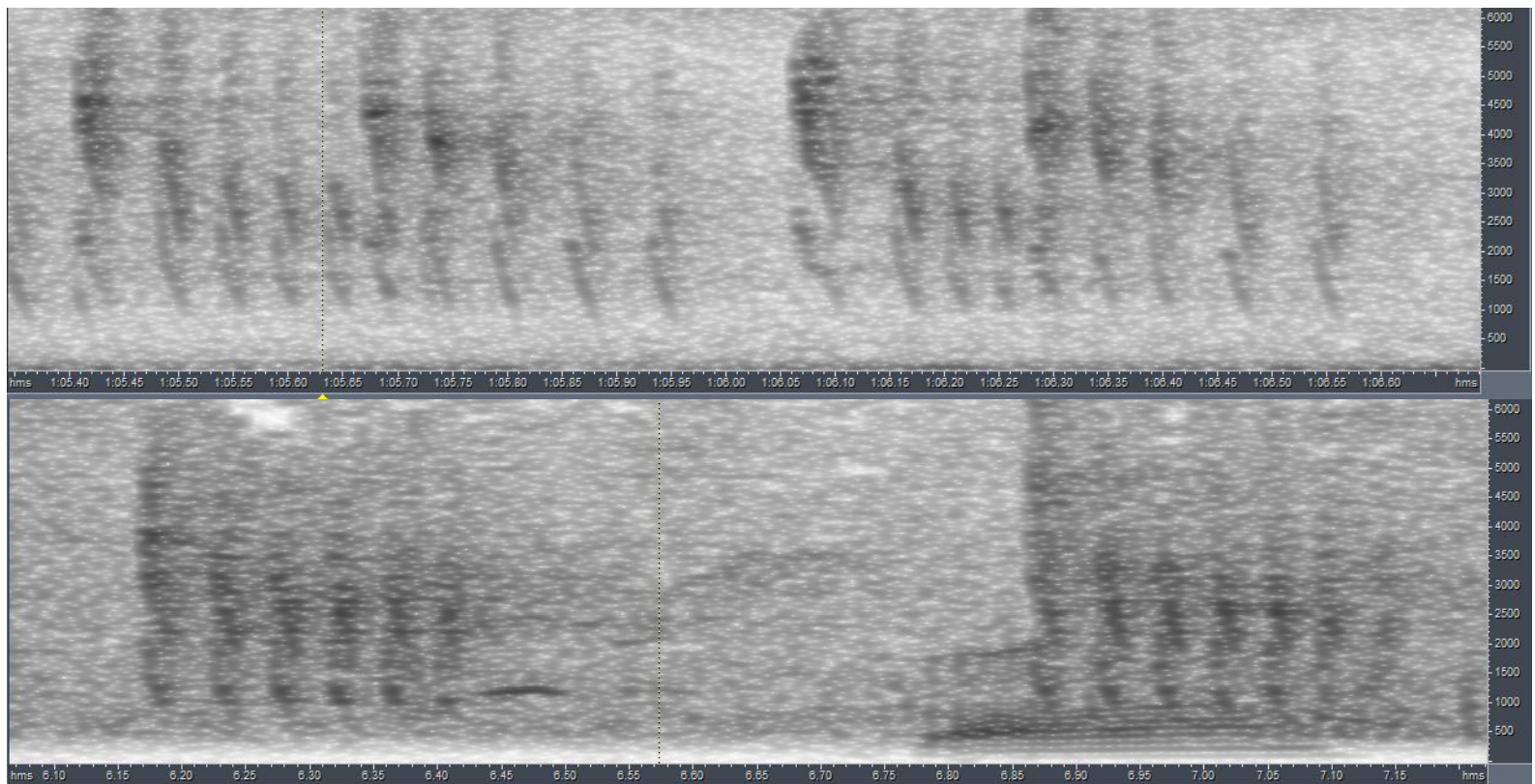

Differences are quite subtle:

dimorpha $(n=8)$

$\min$. freq. $800-1000 \mathrm{~Hz}$, min. note space $0.038-0.048 \mathrm{~s}$

salvo's have on average larger number of notes

This race has the most pronounced rising - falling start of chatter (often absent in other races)

fusciceps $(n=7)$ :

min. freq. $500-600 \mathrm{~Hz}$, min note space $0.037-0.044 \mathrm{~s}$

has on average the shortest chatters with fewest notes

obidensis ( $n=3)$ :

$\min$. freq. $750-950 \mathrm{~Hz}$, min. note space $0.048-0.058 \mathrm{~s}$

fusciceps vs dimorpha

fusciceps has lowest freq. (score 2-3), generally lacks the rising/falling start of dimorpha (score 1) and on average shortest chatters with fewest notes (score 1). This would lead to a total vocal score of 3-4 when applying Tobias criteria. 

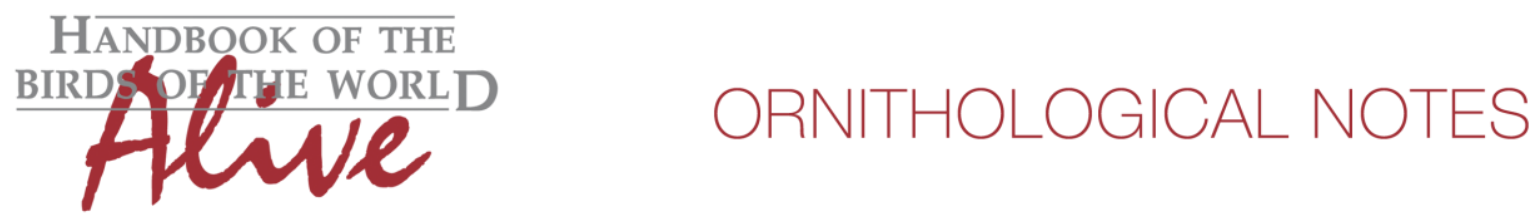

fusciceps vs. obidensis

fusciceps has lowest freq. (score 2-3) and on average shortest chatters with fewest notes (score 0-1). Total score about 3.

dimorpha vs. obidensis

dimorpha has slightly faster chatter pace (score 1-2), generally has a rising-falling start (score 1) and on average slightly longer chatters with more notes (score 0-1). Total score 2-3.

In summary, fusciceps is vocally most distinct.

Vocal difference between dimorpha and obidensis is quite small (hardly discernable by ear, the apparent lack of rising/falling pitch in obidensis being the best distinguishing feature(but caution needed, $n=3$ !)).

This note was finalized on 11th January 2016, using sound recordings available on-line at that moment. We would like to thank in particular the sound recordists who placed their recordings for this species on XC and ML: Peter Boesman, Bradley Davis, Paul Donahue, Bennett Hennessey, Steven Hilty, David Geale, Sebastian Herzog, Daniel Lane, Gabriel Leite, Curtis Marantz, Ted Parker, Glenn Seeholtzer, Joseph Tobias, Arnoud van den Berg and Krysztof Zyskowski

\section{References}

Tobias, J.A., Seddon, N., Spottiswoode, C.N., Pilgrim, J.D., Fishpool, L.D.C. \& Collar, N.J. (2010). Quantitative criteria for species delimitation. Ibis 152(4): 724-746.

\section{Recommended citation}

Boesman, P. (2016). Notes on the vocalizations of Plain Softtail (Thripophaga fusciceps). HBW Alive Ornithological Note 99. In: Handbook of the Birds of the World Alive. Lynx Edicions, Barcelona. (retrieved from http://www.hbw.com/node/932004 on 20 July 2016). 